\title{
Zonal asymmetry of daytime 150-km echoes observed by Equatorial Atmosphere Radar in Indonesia
}

\author{
T. Yokoyama ${ }^{1}$, D. L. Hysell ${ }^{1}$, A. K. Patra ${ }^{2}$, Y. Otsuka ${ }^{3}$, and M. Yamamoto ${ }^{4}$ \\ ${ }^{1}$ Department of Earth and Atmospheric Sciences, Cornell University, Ithaca, NY, USA \\ ${ }^{2}$ National Atmospheric Research Laboratory, Gadanki, India \\ ${ }^{3}$ Solar-Terrestrial Environment Laboratory, Nagoya University, Nagoya, Japan \\ ${ }^{4}$ Research Institute for Sustainable Humanosphere, Kyoto University, Uji, Japan
}

Received: 7 July 2008 - Revised: 2 February 2009 - Accepted: 6 February 2009 - Published: 2 March 2009

\begin{abstract}
Multi-beam observations of the daytime ionospheric E-region irregularities and the so-called $150-\mathrm{km}$ echoes with the 47-MHz Equatorial Atmosphere Radar (EAR) in West Sumatra, Indonesia $\left(0.20^{\circ} \mathrm{S}, 100.32^{\circ} \mathrm{E}\right.$, $10.36^{\circ} \mathrm{S}$ dip latitude) are presented. $150-\mathrm{km}$ echoes have been frequently observed by the EAR, and their characteristics are basically the same as the equatorial ones, except for an intriguing zonal asymmetry; stronger echoes in lower altitudes in the east directions, and weaker echoes in higher altitudes in the west. The highest occurrence is seen at $5.7^{\circ}$ east with respect to the magnetic meridian, and the altitude gradually increases as viewing from the east to west. Arc structures which return backscatter echoes are proposed to explain the asymmetry. While the strength of radar echoes below $105 \mathrm{~km}$ is uniform within the wide coverage of azimuthal directions, the upper E-region (105-120 km) echoes also show a different type of zonal asymmetry, which should be generated by an essentially different mechanism from the lower E-region and 150-km echoes.
\end{abstract}

Keywords. Ionosphere (Equatorial ionosphere; Ionospheric irregularities) - Radio science (Remote sensing)

\section{Introduction}

Daytime radar echoes from meter-scale irregularities, which occur between 130 and $170 \mathrm{~km}$ altitude in the equatorial ionosphere, the so-called $150-\mathrm{km}$ echoes, have been a puzzling phenomenon since Balsley (1964) discovered them more than 40 years ago because there are no obvious free

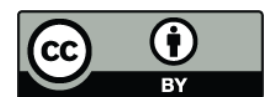

Correspondence to: T. Yokoyama (ty78@cornell.edu) energy source at those altitudes. Kudeki and Fawcett (1993) conducted high resolution observations with the Jicamarca radar and showed that $150-\mathrm{km}$ echoes have necklace-like patterns in range-time-intensity (RTI) plots and that gravity waves seem to play an important role in the generation of $150-\mathrm{km}$ echoes. Understanding the $150-\mathrm{km}$ echoes is important because the Doppler velocities of $150-\mathrm{km}$ echoes represent the $\boldsymbol{E} \times \boldsymbol{B}$ drift velocities at F-region altitudes (e.g., Chau and Woodman, 2004). Although some models have been proposed to explain the nature of $150-\mathrm{km}$ echoes (e.g., Tsunoda and Ecklund, 2008), a source mechanism has not yet been identified.

Until recently, $150-\mathrm{km}$ echoes were only observed by radars located within the equatorial electrojet belt and were believed to be specific to the equatorial ionosphere. However, Choudhary et al. (2004) and Patra and Rao (2006) found $150-\mathrm{km}$ echoes with the Gadanki radar in India $\left(6.3^{\circ} \mathrm{N}\right.$ dip latitude), and Patra et al. (2008) found them with the Equatorial Atmosphere Radar (EAR) in Indonesia $\left(10.36^{\circ} \mathrm{S}\right.$ dip latitude). Patra et al. (2008) showed that the vertical and zonal drift velocities estimated from the multi-beam observation were consistent with the background daytime electric field. The major difference between these low-latitude stations and the equatorial ones is that the geomagnetic field over the low-latitude stations is connected with the $\mathrm{F}$ region over the dip equator so that the F-region dynamo may affect $150-\mathrm{km}$ echoes. Observations in the low-latitude location will continue to further our understanding of $150-\mathrm{km}$ echoes.

Anisotropy in the angular distribution of $150-\mathrm{km}$ echoes is also puzzling. Although the echoes are aspect sensitive and have narrow spectral widths $\left(<15 \mathrm{~m} \mathrm{~s}^{-1}\right)$, their spectral widths measured a few degrees off-perpendicular to $\mathbf{B}$ are quite wide (>1000 $\mathrm{m} \mathrm{s}^{-1}$ ) (Chau, 2004). Kudeki et al. (1998)

Published by Copernicus Publications on behalf of the European Geosciences Union. 
Table 1. Experimental specifications used for the observations.

\begin{tabular}{|c|c|c|}
\hline Parameter & Normal & High resolution \\
\hline & $10-16$ Oct 2007 & \multirow{3}{*}{$2 \mathrm{Feb} 2008$} \\
\hline \multirow[t]{2}{*}{ Period } & 19-26 Nov 2007 & \\
\hline & 12-17 Dec 2007 & \\
\hline Beam directions, deg. & $20.8 \mathrm{E}(135.0,28.59)$ & $12.4 \mathrm{E}(150.0,24.03)$ \\
\hline \multirow[t]{7}{*}{ (Azimuth, Zenith) } & $12.4 \mathrm{E}(150.0,24.03)$ & $5.7 \mathrm{E}(165.0,21.84)$ \\
\hline & $5.7 \mathrm{E}(165.0,21.84)$ & $0.2 \mathrm{~W}(180.0,21.23)$ \\
\hline & $0.2 \mathrm{~W}(180.0,21.23)$ & $6.1 \mathrm{~W}(195.0,21.98)$ \\
\hline & $6.1 \mathrm{~W}(195.0,21.98)$ & \\
\hline & $12.9 \mathrm{~W}(210.0,24.36)$ & \\
\hline & $21.7 \mathrm{~W}(225.0,29.23)$ & \\
\hline & $35.0 \mathrm{~W}(239.9,38.86)$ & \\
\hline Range, km & \multicolumn{2}{|c|}{$90.0-219.6$} \\
\hline Range resolution, $\mathrm{km}$ & \multicolumn{2}{|c|}{1.2} \\
\hline Interpulse period, $\mathrm{ms}$ & \multicolumn{2}{|c|}{1.6} \\
\hline FFT points & \multicolumn{2}{|c|}{256} \\
\hline Coherent integration & \multicolumn{2}{|c|}{8} \\
\hline Incoherent integration & \multicolumn{2}{|c|}{5} \\
\hline Pulse code & \multicolumn{2}{|c|}{ 8-bit complementary code } \\
\hline Operation mode & With ST & Without ST \\
\hline Time resolution, $\mathrm{s}$ & 344 & 82 \\
\hline
\end{tabular}

conducted three-beam observations (vertical and $\pm 14^{\circ}$ in the magnetic east-west plane) using a radar at Pohnpei $\left(0.3^{\circ} \mathrm{N}\right.$ dip latitude). They showed that the echoes in the oblique beams were stronger than those in the vertical one. Tsunoda and Ecklund (2000) indicated that the echoes in the west beam have a larger intensity than those in the east beam. The same feature can be seen in the results shown by Kudeki et al. (1998) although they did not mention it. On the other hand, Tsunoda and Ecklund (2007) used five beams (vertical, $\pm 14.3^{\circ}$ and $\pm 29.5^{\circ}$ in the magnetic east-west plane) and showed that echoes from $14.3^{\circ}$ east are stronger than those from vertical and $14.3^{\circ}$ west, but their altitude is not different between three directions. They also showed that echoes from $\pm 29.5^{\circ}$ are very weak and concluded that $150-\mathrm{km}$ echoes appear in a narrow range of zenith angles. Patra et al. (2008) also showed the east-west asymmetry of $150-\mathrm{km}$ echoes from the initial results with the EAR: echoes in the east beam were stronger than those in the west beam. After the report by Patra et al. (2008), the zonal asymmetry has turned out to be a general feature in $150-\mathrm{km}$ echoes. In addition, a different type of asymmetry has been seen in the upper E-region $(105-120 \mathrm{~km})$ echoes observed simultaneously. The zonal asymmetry of the 150-km and the upper E-region echoes observed by the EAR are discussed in the present paper.

\section{Experimental description}

The 47-MHz Equatorial Atmosphere Radar (EAR) in West Sumatra, Indonesia $\left(0.20^{\circ} \mathrm{S}, 100.32^{\circ} \mathrm{E}, 10.36^{\circ} \mathrm{S}\right.$ dip latitude) has an active phased-array antenna system which allows rapid beam scanning on a pulse-to-pulse basis (Fukao et al., 2003). It has a peak transmitting power of $100 \mathrm{~kW}$ and
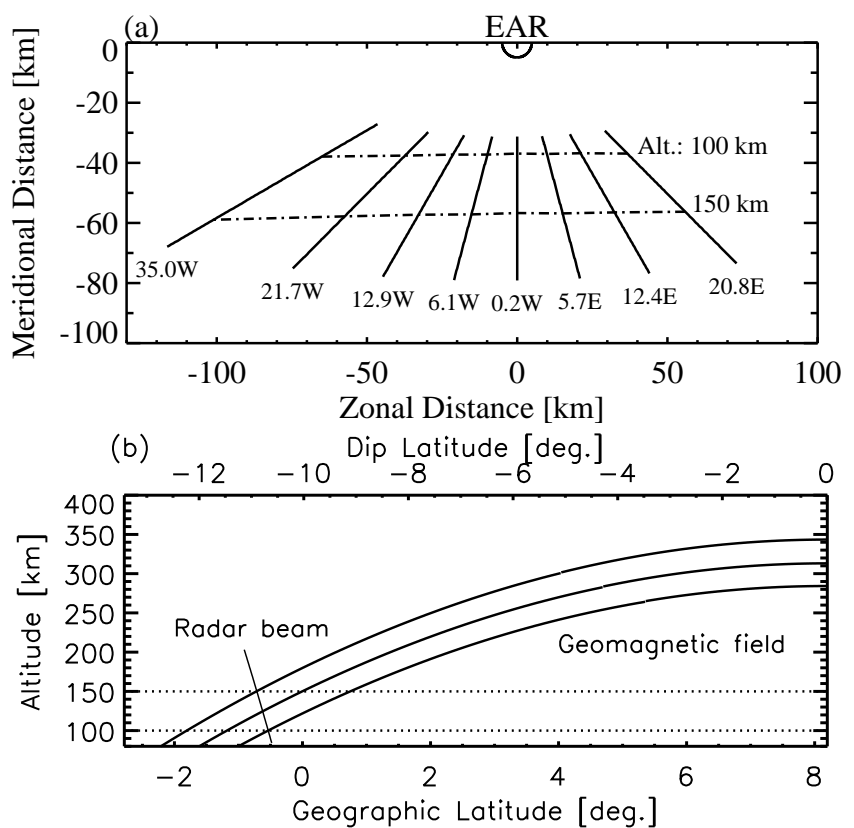

(c) Beam patterns and loci of perpendicularity

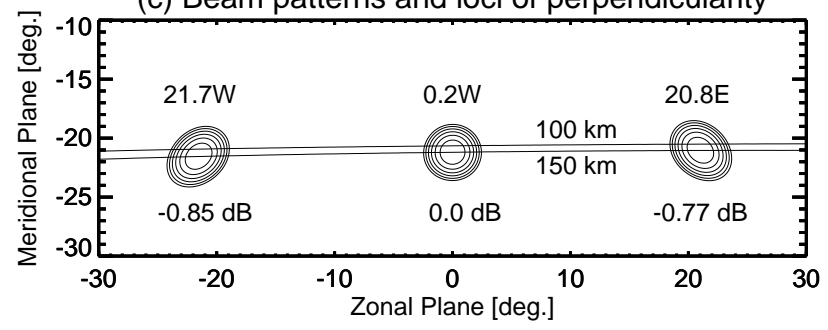

Fig. 1. (a) Radar beam directions projected on the horizontal plane. (b) Latitude-altitude cross section of $0.2 \mathrm{~W}$ and geomagnetic field along a magnetic meridian. (c) Beam patterns of three directions (20.8 E, $0.2 \mathrm{~W}$ and $21.7 \mathrm{~W}$ ) and loci of perpendicularity at altitudes of $100 \mathrm{~km}$ and $150 \mathrm{~km}$. Values in $\mathrm{dB}$ are peak power at boresights relative to $0.2 \mathrm{~W}$. Contours are drawn every $1 \mathrm{~dB}$.

a one-way half-power beam width of $3.4^{\circ}$. We conducted two experiments: one in October to December 2007 (normal) and the other on 2 February 2008 (high resolution). Experimental specifications are shown in Table 1. Eight azimuth directions (from geographic north) were chosen in the normal mode, and a zenith angle for each azimuth was set to be perpendicular to $\mathbf{B}$ field at an altitude of $150 \mathrm{~km}$. The angles with respect to the magnetic meridian are used to identify each beam ( $20.8 \mathrm{E}$ represents $20.8^{\circ}$ to the east from the magnetic meridian). The normal mode was operated by alternating with stratosphere and troposphere (ST) observations. One set of operations used two beam directions with pulseto-pulse steering and with an unambiguous Doppler velocity of $\pm 62.3 \mathrm{~m} \mathrm{~s}^{-1}$. The ST observations were made between the two sets (four beams) of observations and the next two sets. ST observations were stopped in the high resolution mode on 2 February 2008, and the number of beam directions was 
reduced so that the time resolution could be improved from $344 \mathrm{~s}$ to $82 \mathrm{~s}$. The radar beam configuration in the horizontal plane and the latitude-altitude cross section for $0.2 \mathrm{~W}$ highlighting the geomagnetic field are shown in Fig. 1a and b, respectively. The horizontal coverage of the eight-beam observations at an altitude of $150 \mathrm{~km}(100 \mathrm{~km})$ is about $160 \mathrm{~km}$ $(100 \mathrm{~km})$. The altitude range of $100-150 \mathrm{~km}$ observed by the EAR maps to a range of $284-344 \mathrm{~km}$ over the dip equator. Therefore, the E region observed by the EAR is directly coupled with the $\mathrm{F}$ region, which is different from radars located at the dip equator such as Jicamarca and Pohnpei. Figure 1c shows beam patterns for three directions and loci of perpendicularity at altitudes of $100 \mathrm{~km}$ and $150 \mathrm{~km}$. Because of the distortion of the beam pattern with a larger zenith angle, peak power at boresights drops $\sim 0.8 \mathrm{~dB}$ relative to the central beam direction. However, the zonal asymmetry of echo intensity shown in the next section is much stronger than that expected from the differential gain in the beam patterns. The asymmetry of the upper E-region echoes should also be of relevance because the locus at $100 \mathrm{~km}$ passes within $1-\mathrm{dB}$ down contours for all directions.

\section{Results}

We observed 150-km echoes on 13 days out of 21 days of observations made in the normal mode during the OctoberDecember 2007 period (one day in October, seven days in November, and five days in December), and also with the high-resolution mode on 2 February 2008. All of them have a distinct east-west asymmetry of $150-\mathrm{km}$ echoes in echo intensity and altitude. The high resolution result is shown first, and averaged features from the normal mode are shown later.

\subsection{High resolution mode on 2 February 2008}

Figure 2a shows RTI plots of signal-to-noise ratio (SNR) of the backscatter echoes obtained by the high resolution mode on 2 February 2008. Strong E-region echoes are seen between 90 and $110 \mathrm{~km}$ altitudes, and typical $150-\mathrm{km}$ echoes with a necklace shape are seen between 145 and $170 \mathrm{~km}$ in all directions. Because the EAR location is far out of the electrojet belt and the spectra of the E-region echoes are wide $\left(\sim 30 \mathrm{~m} \mathrm{~s}^{-1}\right)$ compared to the mean Doppler velocity $\left(\sim \pm 10 \mathrm{~m} \mathrm{~s}^{-1}\right)$, the echoes are essentially type- 2 in nature and hence can be regarded as arising from the gradient drift instability. Although the intensity of the E-region echoes is uniform between the four directions, the $150-\mathrm{km}$ echoes show a distinct east-west asymmetry, that is, strong echoes in the east directions and weak echoes in the west as shown by Patra et al. (2008). Figure $2 \mathrm{~b}$ shows the time variation of the maximum SNR and altitude of the $150-\mathrm{km}$ echoes. Interestingly, the echo intensity was drastically increased ( $\sim 20 \mathrm{~dB})$ between 11:00 LT and 13:00 LT in the east directions (12.4 E and 5.7 E), whereas there were no signifi-
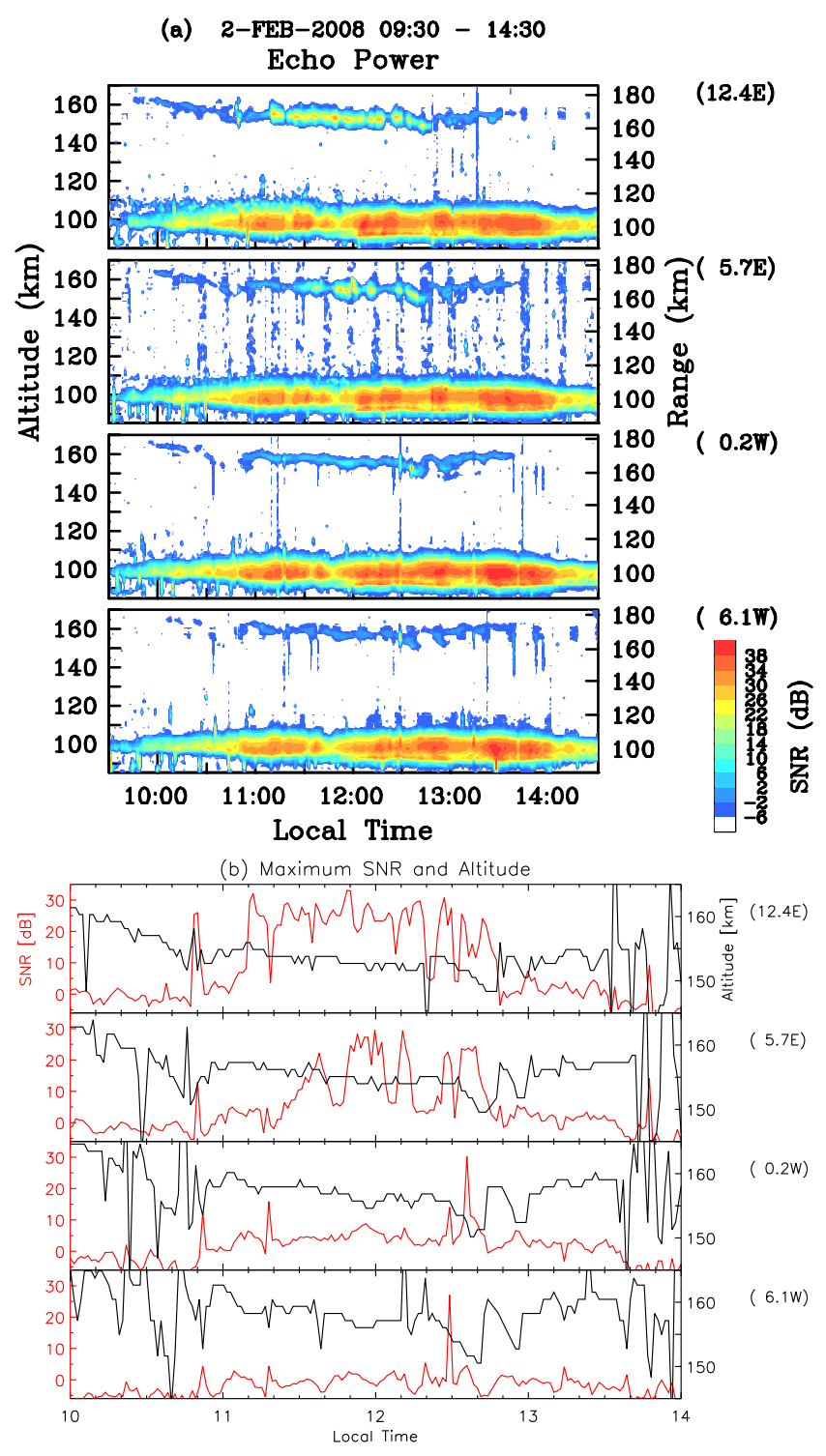

Fig. 2. (a) Range-time-intensity (RTI) plots of signal-to-noise ratio (SNR) of the backscatter echoes obtained by the high resolution mode on 2 February 2008. (b) Time variation of the maximum SNR and altitude of $150-\mathrm{km}$ echoes.

cant changes in $0.2 \mathrm{~W}$ and $6.1 \mathrm{~W}$. Solar and magnetic activity did not change so drastically during the period. The asymmetry is unlikely to be due to any instrumental issues because the low altitude echo intensities are uniform across the four directions. Because the spectral widths of $150-\mathrm{km}$ echoes in all directions are narrow (Patra et al., 2008), it is not likely that these echoes come from an off-perpendicular direction (Chau, 2004).

In order to see the small-scale structure of $150-\mathrm{km}$ echoes, the 150-km region is expanded in Fig. 3 (see also Fig. 2b). It is clearly seen that SNR is modulated with a period of 


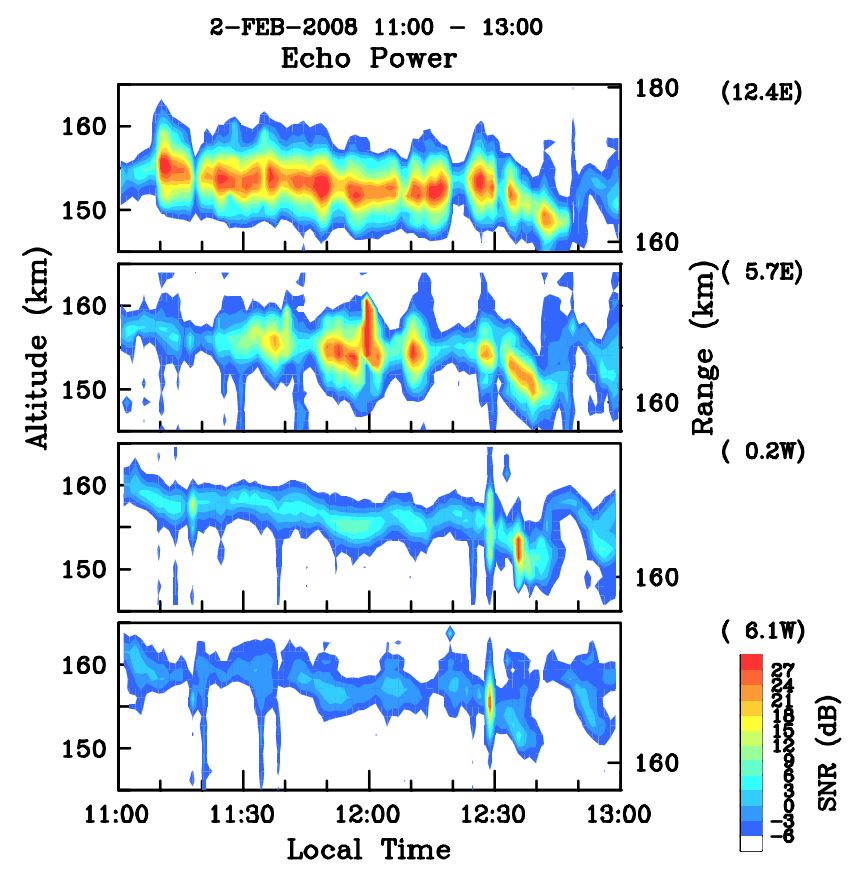

Fig. 3. Same as Fig. 2a except the 150-km region is expanded.

5-10 min, especially in the east directions, which resemble the equatorial 150-km echoes (e.g., Kudeki and Fawcett, 1993). Furthermore, the echo altitude is also modulated, with an amplitude of $10 \mathrm{~km}$ between 12:20 LT and 13:00 LT. The modulation pattern seems to have propagated from the west to east although the zonal drift velocity has a westward component (see Fig. 4). It may be possible that eastward propagating gravity waves passed through this region and modulated the altitude of $150-\mathrm{km}$ echoes. Focusing on a relative echo altitude between the four directions, $150-\mathrm{km}$ echoes appear at lower altitude in the east beam and higher altitude in the west beam as compared to that of $0.2 \mathrm{~W}$ (nearly along the magnetic meridian). For example, the central altitude of the echoes at 12:00 LT is $152 \mathrm{~km}$ in $12.4 \mathrm{E}$ and $158 \mathrm{~km}$ in $6.1 \mathrm{~W}$. The relative altitude difference at Pohnpei was also reported by Tsunoda and Ecklund (2000) and can be seen in a figure of Kudeki et al. (1998), but higher altitude echoes were detected in the east beam in their cases.

Figure 4a shows RTI plots of Doppler velocity of the backscatter echoes obtained by the high resolution mode on 2 February 2008. Positive (negative) Doppler velocity indicates a line-of-sight motion toward (away from) the EAR. Doppler velocities of $150-\mathrm{km}$ echoes seem similar to the upper part of the E-region echoes $(100-110 \mathrm{~km})$ but significantly different from the lower E-region echoes. The zonal and vertical (perpendicular to B) drift velocities of $150-\mathrm{km}$ and upper E-region echoes derived from the line-of-sight velocities are shown in Fig. 4b. Velocity data with SNR over $0 \mathrm{~dB}$ are averaged over 30 -min time bins and the $145-165 \mathrm{~km}$
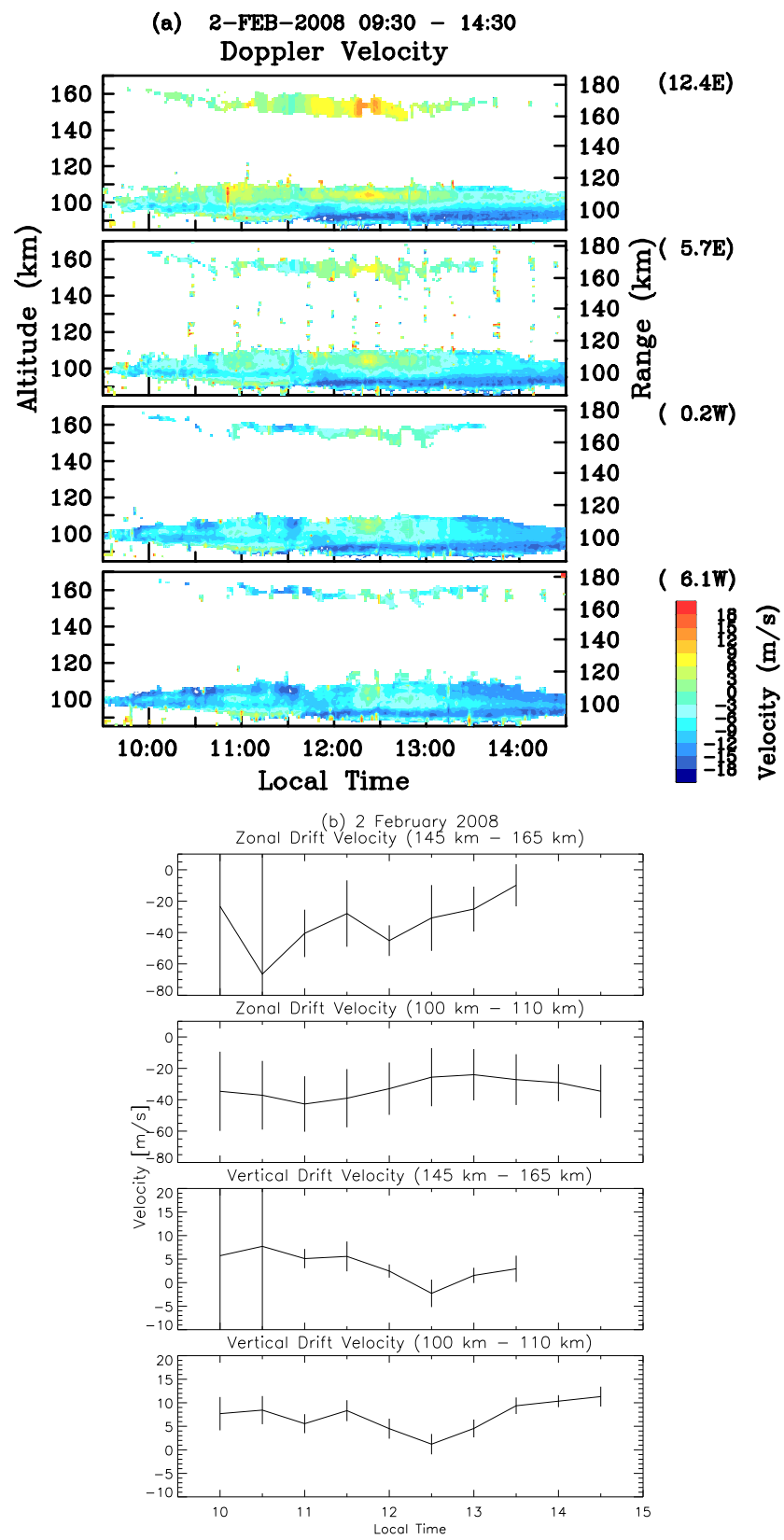

Fig. 4. (a) RTI plots of Doppler velocity of the backscatter echoes obtained by the high resolution mode on 2 February 2008. Positive (negative) Doppler velocity indicates a line-of-sight motion toward (away from) the EAR. (b) Zonal and vertical drift velocities of 150$\mathrm{km}$ and upper E-region echoes derived by the least-square method. Vertical bars represent standard deviation.

(100-110 km) altitude range for the 150-km (upper E-region) echoes. Vertical bars represent the standard deviation. The vertical velocities in the two regions show quite similar time variation, that is, an upward component of $0-10 \mathrm{~m} \mathrm{~s}^{-1}$ during the period and a downward shift between 12:00 LT and 


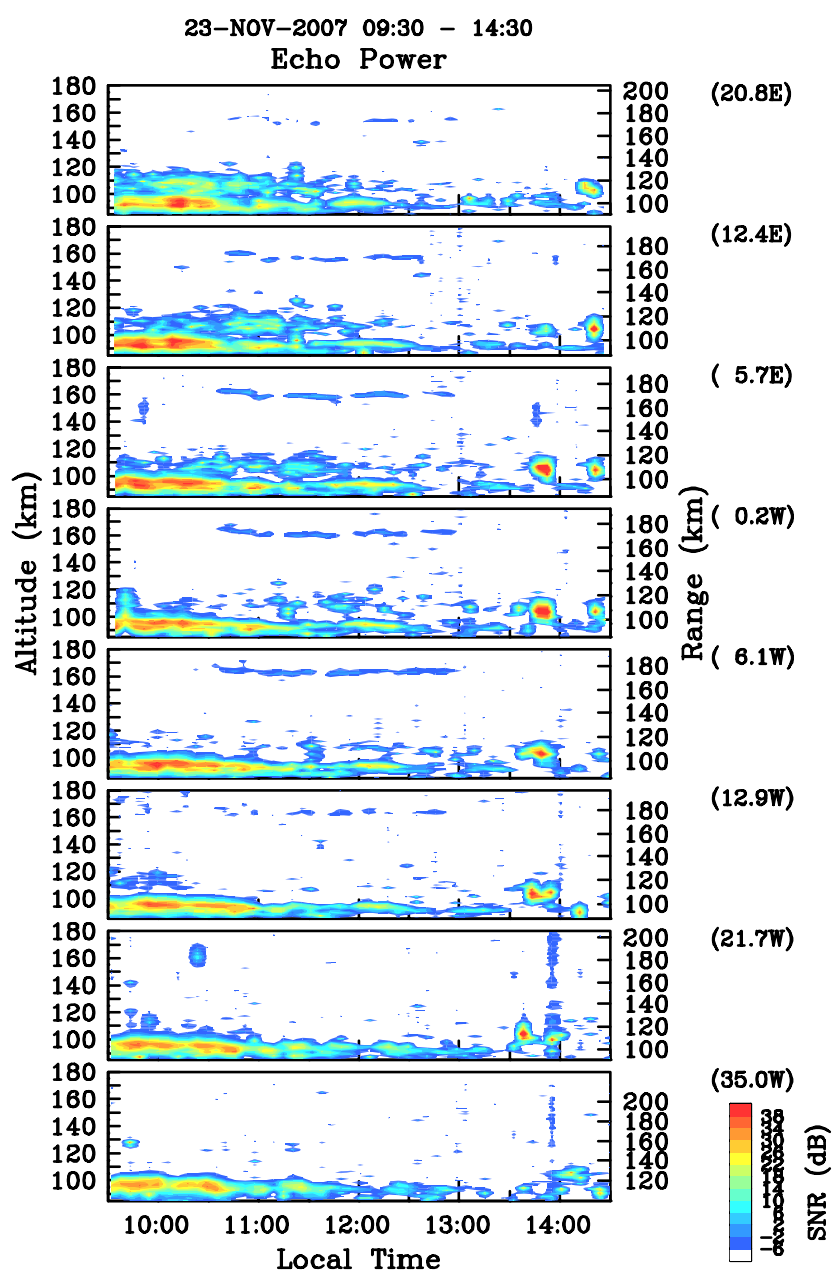

Fig. 5. RTI plots of SNR and Doppler velocity of the backscatter echoes obtained by the normal mode on 23 November 2007.

13:00 LT. As shown in Fig. 1b, the E-region observed by the EAR is coupled to the $150-\mathrm{km}$ region closer to the dip equator. Therefore, it is reasonable that the vertical velocities in both regions are controlled by the same electrodynamics. The velocity of the upper E-region echoes is a few meters per second larger than that of the $150-\mathrm{km}$ echoes. As ions are unmagnetized below $\sim 120 \mathrm{~km}$, the difference is probably due to the line-of-sight component of the southward neutral wind. In fact, the Doppler velocities below $100 \mathrm{~km}$, where the Doppler velocity is attributed to the neutral wind $(\mathrm{Pa}-$ tra et al., 2007), have a negative component (away from the radar) in all directions, which implies a southward neutral wind throughout the region. The zonal drift velocities, on the other hand, have a westward component in both regions, but the variation is not so similar because the neutral wind contribution to the zonal velocity is much larger than to the vertical one.
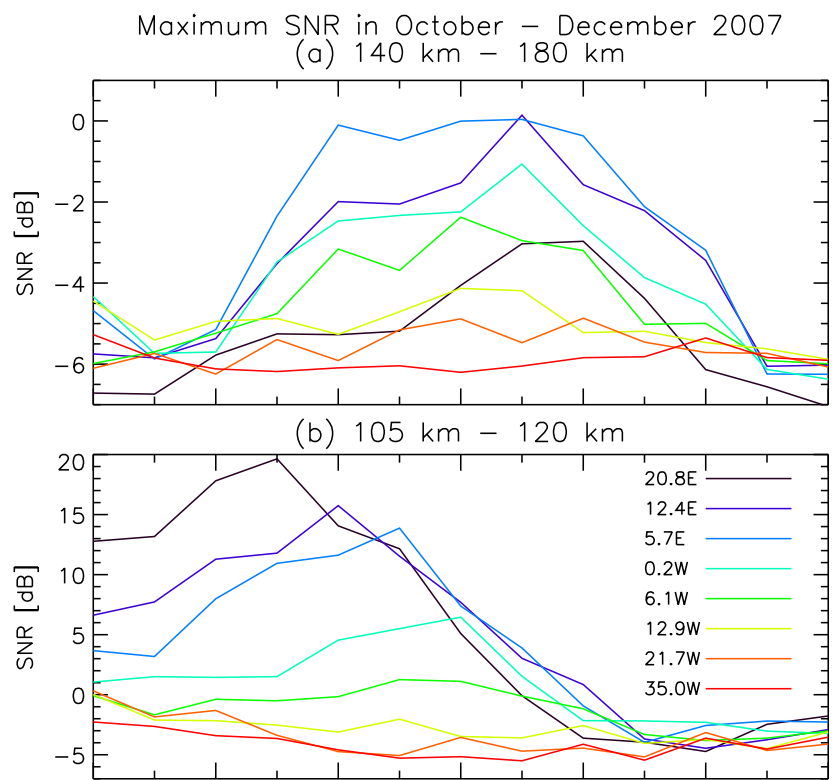

(c) $90 \mathrm{~km}-97 \mathrm{~km}$

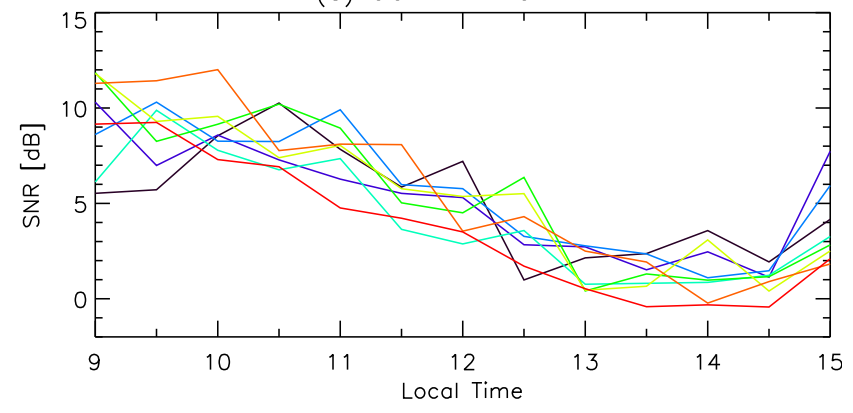

Fig. 6. Maximum SNR of (a) 150-km, (b) upper E-region, and (c) lower E-region echoes averaged for 13 days during the normal mode observation. Beam directions are represented by different colors.

\subsection{General features of E-region and 150-km Echoes}

A typical example which represents the characteristics of the E-region and $150-\mathrm{km}$ echoes obtained during the normal mode observation is shown in Fig. 5. Three echoing regions are discernible in these panels; a lower E region (85$105 \mathrm{~km})$, an upper E region (105-120 km), and a $150-\mathrm{km}$ region. Two general characteristics of $150-\mathrm{km}$ echoes observed by the EAR are noted: (1) $150-\mathrm{km}$ echoes occur intermittently with a period of $20-30 \mathrm{~min}$, and (2) the $150-\mathrm{km}$ echoes observed by the EAR are narrower than in the equatorial cases and never seen as a multi-layer structure (e.g., Kudeki and Fawcett, 1993). In addition, 150-km echoes as well as the upper E-region echoes show different types of anisotropy, whereas the lower E-region echoes are almost uniform in all directions. The upper E-region echoes are the strongest in the easternmost beam and are monotonically weakened as viewing from the east to west. On the other 


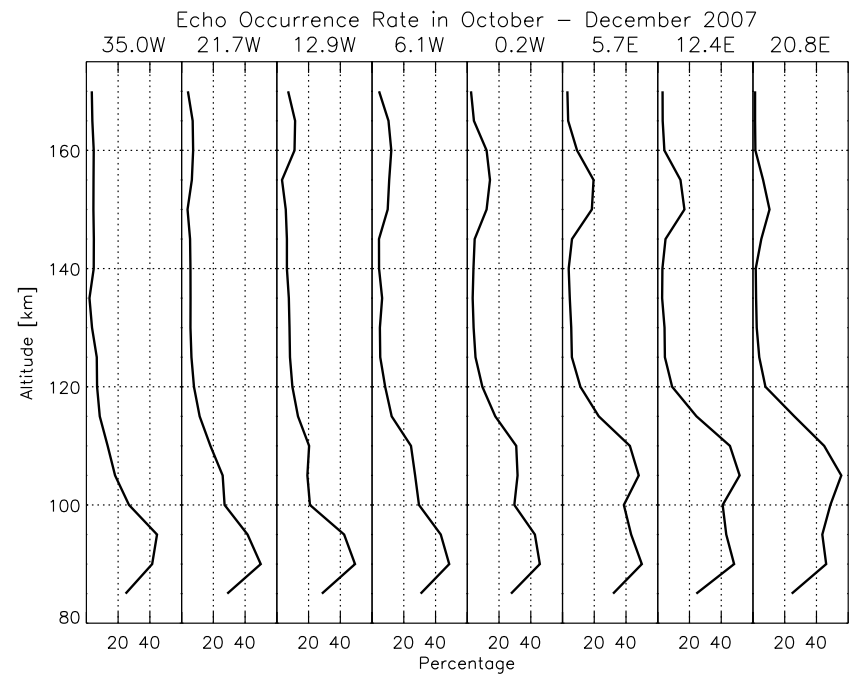

Fig. 7. Occurrence rates of radar echoes of over $-6 \mathrm{~dB}$ between 09:00 LT and 15:00 LT in each direction for 13 days during the normal mode observation.

hand, the $150-\mathrm{km}$ echoes are the strongest in $5.7 \mathrm{E}$, and the altitude monotonically increases as viewing from the east to west. It should again be emphasized that the asymmetry cannot be explained by any instrumental issues because of the uniform lower E-region echoes.

During the October-December 2007 period, 150-km echoes were detected on 13 days by the EAR. Figure 6 shows the maximum SNR of (a) 150-km (140-180 km), (b) upper E-region (105-120 km), and (c) lower E-region (90-97 km) echoes averaged over 30-min time bins for 13 days. Different beam directions are represented by different colors. The SNR of $150-\mathrm{km}$ echoes are the strongest in $5.7 \mathrm{E}$ for most of the period when $150-\mathrm{km}$ echoes appear. It is noted that the SNR difference between the three east directions (20.8 E, 12.4 $\mathrm{E}$ and $5.7 \mathrm{E}$ ) is larger in the morning hours than in the afternoon, and the SNR in $12.4 \mathrm{E}$ becomes comparable to that in 5.7 E after 12:30 LT. As viewing to the west from 5.7 E, the SNR drops every $1-2 \mathrm{~dB}$ in each direction. The upper E-region echoes show clear asymmetry before 10:30 LT as mentioned above, but the SNR in $20.8 \mathrm{E}$ starts to decrease after 10:30 LT. Interestingly, the decrease does not occur simultaneously in all directions but one after another from the east to west. When the decreased SNR in $20.8 \mathrm{E}$ reaches the value in the other direction, the SNR in this direction also starts to decrease at the same rate as that in $20.8 \mathrm{E}$. The four eastern beams $(0.2 \mathrm{~W}-20.8 \mathrm{E})$ have almost the same SNR values at 12:00 LT, while the SNR in the western beams $(6.1 \mathrm{~W}-$ $35.0 \mathrm{~W})$ are still smaller. Finally, the asymmetry in the upper E-region echoes disappears after 13:30 LT. The SNR of the lower E-region echoes gradually decreases with time in all directions, but no significant asymmetry can be seen in the lower E-region echoes.
Figure 7 shows occurrence rate profiles of radar echoes for the 13 days. Echoes with SNR $>-6 \mathrm{~dB}$ between 09:00 LT and 15:00 LT are counted in an altitude bin of $5 \mathrm{~km}$ for each beam direction. The occurrence rates at 90 and $95 \mathrm{~km}$ are $40-50 \%$ at all directions, whereas there is a distinct asymmetry above $100 \mathrm{~km}$. At an altitude of $105 \mathrm{~km}$, for example, $55.7 \%$ in $20.8 \mathrm{E}, 51.6 \%$ in $12.4 \mathrm{E}, 48.0 \%$ in $5.7 \mathrm{E}, 31.7 \%$ in $0.2 \mathrm{~W}$, and below $30 \%$ at the four west directions. On the other hand, the echo occurrence of $\sim 20 \%$ at 150 and $155 \mathrm{~km}$ altitudes in $5.7 \mathrm{E}$ is the highest in the $150-\mathrm{km}$ region. The occurrence is still high in the adjacent directions $(12.4 \mathrm{E}$ and $0.2 \mathrm{~W}$ ) but fairly low in the easternmost direction, which is different from the monotonic variation of upper E-region echoes. Furthermore, the peak altitude gradually increases from $150 \mathrm{~km}$ in $20.8 \mathrm{E}$ to $165 \mathrm{~km}$ in $12.9 \mathrm{~W}$. The zonal asymmetry has turned out to be a general feature of the $150-\mathrm{km}$ echoes as well as the upper E-region echoes observed by the EAR.

\section{Discussion}

In the successive observations since Patra et al. (2008), 150$\mathrm{km}$ echoes have been frequently observed by the EAR. The zonal asymmetry is an intriguing characteristic found by the EAR because its directional dependence is different from that of the equatorial results (Tsunoda and Ecklund, 2000). The zonal asymmetry at Pohnpei might be related to a magnetic declination angle of $6.5^{\circ}$. However, it is not the case for the EAR because the declination angle is only $-0.5^{\circ}$, so that the radar beam configuration is almost symmetric in terms of a magnetic meridian (Fig. 1c). Tsunoda and Ecklund (2000) proposed a model that tilted sheetlike structures exist at two different altitudes in order to explain the zonal asymmetry observed at Pohnpei. They considered $150-\mathrm{km}$ echoes as coming about from the direct excitation of plasma waves by a linear instability due to a local gradient of the sheetlike structures as a source of free energy. The wave vector of the most easily excited mode would be orthogonal to the mean gradient, so that radar echoes could be detected if the angle between a radar beam and the gradient is close to $90^{\circ}$. Sheetlike structures with different tilt angles at two different altitudes could produce higher altitude echoes in the east beam and lower altitude echoes in the west beam. The sheetlike nature of $150-\mathrm{km}$ echoes was also suggested by Tsunoda and Ecklund (2008) based on Doppler velocity variations obtained by a radar located at Christmas Island. Although the concept of Tsunoda and Ecklund (2000) can be applied to the EAR results by changing sheet orientations between two altitudes, it cannot account for the asymmetry in eight-beam observations in which the altitude of $150-\mathrm{km}$ echoes gradually increases as viewing from the east to west.

Based on Tsunoda and Ecklund (2000) and the asymmetry observed by the EAR, a new schematic model of lowlatitude $150-\mathrm{km}$ echoes is proposed in Fig. 8. This figure is 
on a tilted plane perpendicular to $\mathbf{B}$ in which the $\mathbf{B}$ vector points into the page. In order to explain the asymmetry observed by the EAR, the structures should not be tilted sheets in two altitudes but arcs which bulge to the east. Arcs in the figure indicate the regions which return backscatter echoes and the thickness of the arcs represents the intensity of radar echoes produced on the arcs. A radar beam is tangential to a certain point of the arc (marked by a circle) where radar echoes would be detected (Tsunoda and Ecklund, 2000). In the case the arcs bulge to the east, east (west) beams are tangential to the lower (upper) part of the arcs. The fact that the highest echo occurrence is seen in $5.7 \mathrm{E}$ implies that the lower part of the arcs can produce stronger echoes than the upper part. Low echo occurrence in the easternmost (20.8 E) and three west directions $(12.9 \mathrm{~W}-35.0 \mathrm{~W})$ means that the top and bottom of the arcs would have small tilt angles and not be tangential to these beam directions within the echoing region. Figure 8 could also apply to the asymmetry at Pohnpei (Tsunoda and Ecklund, 2000) by changing the arc bulges to the west and be consistent with the concept of tilted sheetlike structure proposed by Tsunoda and Ecklund (2008).

The high resolution observation on 2 February 2008, revealed some interesting features of $150-\mathrm{km}$ echoes: the drastic enhancement of echo intensity between 11:00 LT and 13:00 LT and the altitude modulation between 12:20 LT and 13:00 LT. The altitude modulation occurred in all four directions with the pattern propagating to the east, which seems to be due to eastward propagating gravity waves with a period of $\sim 20 \mathrm{~min}$. The echo altitude changed from $154 \mathrm{~km}$ at $12: 25 \mathrm{LT}$ to $148 \mathrm{~km}$ at $12: 45 \mathrm{LT}$ in $12.4 \mathrm{E}$ and from $158 \mathrm{~km}$ at 12:20 LT to $151 \mathrm{~km}$ at $12: 40 \mathrm{LT}$ in $6.1 \mathrm{~W}$. Although the altitude of the echoes in $6.1 \mathrm{~W}$ went down as low as $151 \mathrm{~km}$ where strong echoes were observed in $12.4 \mathrm{E}$ a few minutes earlier, the echo intensity did not vary significantly during this period. It means that the enhancement of echo intensity did not occur at a certain altitude but was localized either to the east side of the EAR or in the lower part of the arcs. However, it seems unlikely that the region with larger free energy, no matter what it is, stands only in the east side for two hours and never flows into the west side, because the zonal distance between illuminated volumes at an altitude of $150 \mathrm{~km}$ between the adjacent beams is only about $15 \mathrm{~km}$ (Fig. 1a). The enhancement of free energy only in the lower part of the arcs, regardless of their altitude, may be related to the tilt of the arcs. If gravity waves play an important role in exciting 150-km echoes (Kudeki and Fawcett, 1993), gravity wave activity should also be enhanced during this period. When gravity waves pass through the $150-\mathrm{km}$ region, an angle between the phase front of gravity waves and the arcs differs between the upper and lower parts of the arcs. As expected from the altitude modulation mentioned above, eastward propagating gravity waves could be dominant during this period. In this case, free energy could be provided by wind perturbation orthogonal to the gradient of the arcs. Although we still do not have an idea about the source of

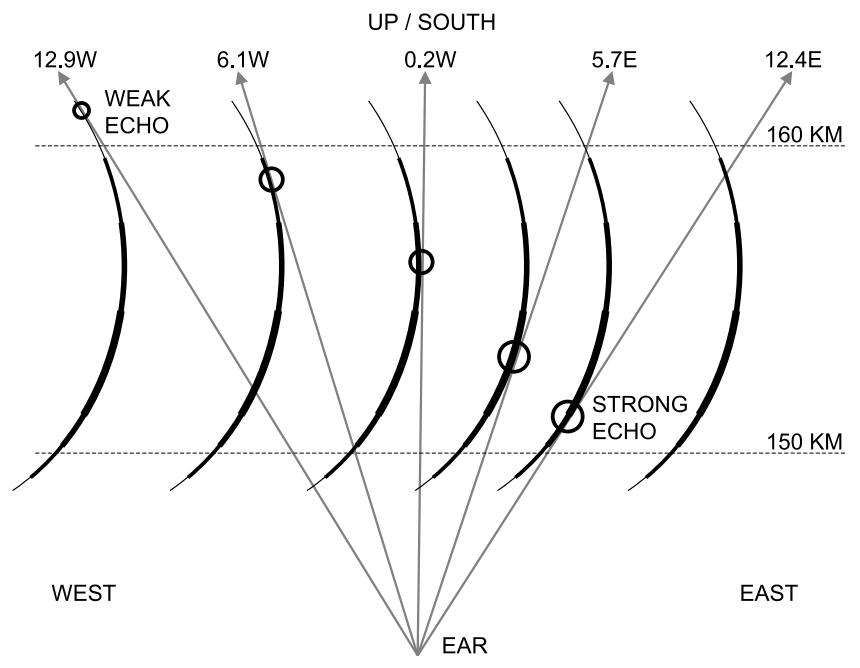

Fig. 8. A schematic model of 150 -km echoes in the low-latitude region. Arcs indicate echoing regions which return backscatter echoes when radar beams are tangential. The thickness of the arcs represents the intensity of backscatter echoes produced on the arcs.

free energy, gravity wave influence may be supported by the present discussion.

The fact that the zonal asymmetry of $150-\mathrm{km}$ echoes in the low-latitude regions is not the same as that of the equator is enigmatic because the other characteristics such as a necklace shape, a gravity wave-like modulation, and outward and westward drifts of irregularities are common. As the EAR is located out of the equatorial electrojet belt but still equatorward of the Sq current focus, both regions are dominated by basically common electrodynamics. The differences between the two regions are the electrojet current at the equator and the F-region dynamo effect in the low latitude. However, the $150-\mathrm{km}$ region over the dip equator is not directly coupled with the electrojet region, and the F-region dynamo effect in the daytime is small because of high conductance in the $\mathrm{E}$ region. We need additional observations to investigate fine zonal structures in the equator and latitudinal structures of $150-\mathrm{km}$ echoes.

It is a new finding that daytime upper E-region (105$120 \mathrm{~km}$ ) irregularities in a low-latitude region also show a zonal asymmetry, which is not typical in the nighttime observations made by the EAR (e.g., Yokoyama et al., 2005). Although this region is coupled with $150-\mathrm{km}$ regions closer to the dip equator (Fig. 1b), the characteristics of the asymmetry are quite different. It is known that radar echoes from the equatorial electrojet show a zonal asymmetry such that the echo intensity in the west beam is stronger than that in the east (e.g., Cohen and Bowles, 1967; Patra et al., 2005), but this is opposite to the EAR results. The monotonic variation of echo intensity in the upper $\mathrm{E}$ region implies a tilted sheetlike structure. Because the asymmetry disappears across the 
different beams, one after another from the east to west, and the SNR in $0.2 \mathrm{~W}$ (geographic south) becomes the same as that in the eastern beams at 12:00 LT, it seems to be related to the solar zenith angle. It is proposed that the upper Eregion irregularities should be generated by an essentially different mechanism than the lower E-region irregularities, but this needs to be investigated further.

\section{Conclusions}

$150-\mathrm{km}$ echoes have been frequently observed by the EAR located in $10.36^{\circ} \mathrm{S}$ dip latitude since the first report by Patra et al. (2008). A necklace shape, a gravity wave-like modulation, and outward and westward drift velocities are the same features as the equatorial results, whereas the narrow and single-layer structures may be specific to the low latitude. A zonal asymmetry has turned out to be a general characteristic of $150-\mathrm{km}$ echoes observed by the EAR. The highest occurrence of $150-\mathrm{km}$ echoes is seen in $5.7 \mathrm{E}$, and the altitude gradually increases as viewing from the east to west. Its directional dependence is different from the equatorial case observed at Pohnpei. It can be explained by the arc structure model shown in Fig. 8. The asymmetry of daytime upper Eregion $(105-120 \mathrm{~km})$ irregularities is also a new finding by the EAR and needs further investigation. The source mechanism of $150-\mathrm{km}$ echoes is still puzzling, however. The spatial structures of $150-\mathrm{km}$ echoes studied in the present paper can help a full understanding of the generation mechanism of $150-\mathrm{km}$ echoes in the future.

Acknowledgements. We thank Jorge L. Chau for helpful discussions. This research was carried out by the collaborative research program of the Research Institute for Sustainable Humanosphere (RISH), Kyoto University. This research was partially supported by Grant-in-Aid for Scientific Research A (20244080) of Japan Society for the Promotion of Science (JSPS) and Grant-in-Aid for Young Scientists A (20684021) of the Ministry of Education, Culture, Sports, Science and Technology of Japan. T. Y. is supported by JSPS Postdoctoral Fellowships for Research Abroad. The operation of EAR is based upon the Agreement between RISH and LAPAN signed on 8 September 2000.

Topical Editor K. Kauristie thanks J. Chau and another anonymous referee for their help in evaluating this paper.

\section{References}

Balsley, B. B.: Evidence of stratified echoing region at $150 \mathrm{~km}$ in the vicinity of magnetic equator during daylight hours, J. Geophys. Res., 69, 1925-1930, 1964.
Chau, J. L.: Unexpected spectral characteristics of VHF radar signals from 150-km region over Jicamarca, Geophys. Res. Lett., 31, L23803, doi:10.1029/2004GL021620, 2004.

Chau, J. L. and Woodman, R. F.: Daytime vertical and zonal velocities from 150-km echoes: Their relevance to F-region dynamics, Geophys. Res. Lett., 31, L17801, doi:10.1029/2004GL020800, 2004.

Choudhary, R. K., St.-Maurice, J.-P., and Mahajan, K. K.: Observation of coherent echoes with narrow spectra near $150 \mathrm{~km}$ altitude during daytime away from the dip equator, Geophys. Res. Lett., 31, L19801, doi:10.1029/2004GL020299, 2004.

Cohen, R. and Bowles, K. L.: Secondary irregularities in the equatorial electrojet, J. Geophys. Res., 72, 885-894, 1967.

Fukao, S., Hashiguchi, H., Yamamoto, M., Tsuda, T., Nakamura, T., Yamamoto, M. K., Sato, T., Hagio, M., and Yabugaki, Y.: Equatorial Atmospheric Radar (EAR): System description and first results, Radio Sci., 38(3), 1053, doi:10.1029/2002RS002767, 2003.

Kudeki, E. and Fawcett, C. D.: High resolution observations of $150 \mathrm{~km}$ echoes at Jicamarca, Geophys. Res. Lett., 20, 19871990, 1993.

Kudeki, E., Fawcett, C. D., Ecklund, W. L., Johnston, P. E., and Franke, S. J.: Equatorial 150-km irregularities observed at Pohnpei, Geophys. Res. Lett., 25, 4079-4082, 1998.

Patra, A. K. and Rao, N. V.: Radar observations of daytime $150-\mathrm{km}$ echoes from outside the equatorial electrojet belt over Gadanki, Geophys. Res. Lett., 33, L03104, doi:10.1029/2005GL024564, 2006.

Patra, A. K., Tiwari, D., Devasia, C. V., Pant, T. K., and Sridharan, R: East-west asymmetries of the equatorial electrojet $8.3 \mathrm{~m}$ type2 echoes observed over Trivandrum and a possible explanation, J. Geophys. Res., 110, A11305, doi:10.1029/2005JA011124, 2005.

Patra, A. K., Yokoyama, T., Yamamoto, M., Nakamura, T., Tsuda, T., and Fukao, S.: Lower E region field-aligned irregularities studied using the Equatorial Atmosphere Radar and meteor radar in Indonesia, J. Geophys. Res., 112, A01301, doi:10.1029/2006JA011825, 2007.

Patra, A. K., Yokoyama, T., Otsuka, Y., and Yamamoto, M.: Daytime 150-km echoes observed with the Equatorial Atmosphere Radar in Indonesia: First results, Geophys. Res. Lett., 35, L06101, doi:10.1029/2007GL033130, 2008.

Tsunoda, R. T., and Ecklund, W. L.: On the nature of 150-km radar echoes over the magnetic dip equator, Geophys. Res. Lett., 27, 657-660, 2000.

Tsunoda, R. T. and Ecklund, W. L.: On the visibility and zenithal confinement of $150 \mathrm{~km}\left(F_{1}\right)$ radar echoes, Geophys. Res. Lett., 34, L21102, doi:10.1029/2007GL031276, 2007.

Tsunoda, R. T. and Ecklund, W. L.: On the sheet-like nature of $150 \mathrm{~km}\left(F_{1}\right)$ radar echoes, Geophys. Res. Lett., 35, L05102, doi:10.1029/2007GL032512, 2008.

Yokoyama, T., Patra, A. K., Fukao, S., and Yamamoto, M.: Ionospheric irregularities in the low-latitude valley region observed with the Equatorial Atmosphere Radar, J. Geophys. Res., 110, A10304, doi:10.1029/2005JA011208, 2005. 